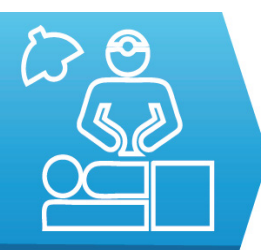

SURGERY

\title{
Early and long-term complications following transanal pull through Soave technique in infants with Hirschsprung's disease
}

Manoochehr Ghorbanpour ${ }^{1}$, Mohammad Ali Seyfrabie ${ }^{2}$, Babak Yousefi ${ }^{1}$

1) Department of Surgery, School of Medicine, Hamadan University of Medical Sciences, Hamadan, IR Iran

2) Department of Social Medicine, School of Medicine, Hamadan University of Medical Sciences, Hamadan, IR Iran
DOI: $10.15386 / \mathrm{mpr}-1314$

Manuscript received: 20.02.2019

Received in revised form: 21.04.2019

Accepted: 07.05.2019

Address for correspondence: amamali110@gmail.com

\begin{abstract}
Background and aim. Patients undergoing Soave surgery for Hirschsprung's disease are at risk for some complications. The aim of this study was to investigate such short-term and long-term complications and evaluate the outcome of the operation in these patients.

Methods. A case series study was carried out during the last 12 years, during 2007 to 2018 in Besat hospital of Hamadan. Data collection conducted using a checklist includes questions about demographic information, clinical features, and shortterm and long-term complications, and consequences of post-operative surgery. The findings of the study were analyzed using SPSS software version 20 and appropriate statistical tests. P-value less than 0.05 was considered statistically significant.

Results. A total of 55 children underwent Soave surgery during the last 12 years in Besat Hospital Hamadan, Iran. The mean age of the patients was $38 \pm 10$ days during surgery, of which $56.4 \%$ were female. The mean hospital stay was 7.3 days. Also, the mean weight of children at birth was $2970 \pm 447$ gr. Most of the patients were born as NVD (52.7\%) and term (74.5\%). The most common comorbidity was congenital heart disease. The most common short-term complication was intestinal obstruction in 14 patients $(25.5 \%)$ and the most frequent long-term complication was intestinal obstruction and constipation ( $27.3 \%$ each cases). The mortality rate of patients in this study was $14.5 \%$ in total.

Conclusions. One stage surgical procedure in Hirschsprung's disease is a safe and effective method, but care should be taken in choosing patients and patients should be monitored for possible complications, so that they can be considered and implemented for proper treatment
\end{abstract}

Keywords: Hirschsprung disease, complications, Soave method, pediatric surgery

\section{Introduction}

Hirschsprung's disease (congenital aganglionic megacolon) is an intestinal motility disorder characterized by the absence of submucosal ganglion cells (Meissner plexus) or myenteric (Auerbach plexus) in the distal part of large intestine. Dysmotility of the affected segment may lead to some complications such as functional intestinal obstruction [1]. Surgery is one of the most commonly used therapeutic modality for children [2,3]. Its pathogenesis is not precisely understood, and various theories have been proposed. The most accepted hypothesis of the etiology of Hirschsprung disease (HD) is that there is a defect in the craniocaudal migration of neuroblasts originating from the neural crest, a process that occurs during embryonic development between the $4^{\text {th }}$ and $12^{\text {th }}$ week of pregnancy [4]. The short-segment HD is common and occurs in the rectosigmoid region. Longsegment HD ( $15 \%-20 \%$ of the cases) may affect the entire colon [5]. Approximately $50 \%$ of affected individuals have some genetic abnormalities [6]. The disease is more common in boys than in girls [7]. Clinical manifestations of the disease range from the infant's bowel obstruction to progressive chronic constipation at an older age. Approximately $80 \%$ of patients experience intestinal motility problems, malnutrition, and progressive abdominal 
distension in their early years [7]. Manifestations of the disease appear in only 20 to 40 percent of newborns in Africa, while the rate is up to $90 \%$ in affected children in developed countries [8-12]. Diagnosis is based on clinical examination, radiographic studies, and histological interpretation of biopsy specimens [13]. The first successful treatment was performed about 60 years ago. The primary surgical procedure for the disease includes releasing of the distal colon involved in the pelvis through extrarectal submucosal dissection up to $2 \mathrm{~cm}$ above the dentate line and creating end-to-end anastomosis [14-18]. Currently, various surgical techniques are used for HD such as Swenson, Soave and others $[19,20]$. But there are few reports of the success or failure rates of these techniques. Patients diagnosed with Hirschsprung's disease are undergoing corrective surgery. More than half a century has now come to discover the causes and treatment of Hirschsprung's disease, and several surgical procedures have been developed which have less technical difficulty and better results.

\section{Objectives}

Considering the prevalence of this disease and the importance of the performed surgical technique, we decided to evaluate the early and late complications following transanal pull through Soave technique in our study.

\section{Methods}

\section{Study population}

We conducted a case-series study and identified all pediatric patients with the diagnosis of Hirschsprung disease (HSCR) who underwent transanal Soave pullthrough procedures in the Department of Pediatric Surgery of Besat Hospital. All children who underwent surgery from January 2007, to December 2018, were considered for this investigation. The diagnosis of HSCR in our center was established according to the clinical manifestation and histopathology findings. The two-staged Soave procedure was conducted for all participants. Moreover, all operations were performed by an experienced pediatric surgeon.

\section{Data collection}

Data extracted from a predesigned checklist included details on patient demographics, comorbidities (major cardiac anomaly, trisomy 21, and other syndromes), birth weight, mode of delivery, early and late complications occurred such as: infection, obstruction, stenosis, anastomosis leak, constipation, enterocolitis, incontinency and mortality. All patients were evaluated for these data at the hospital or by telephone.

Ethical approval for this study was obtained from the Hamadan University of Medical Sciences Ethical Review Committee. The information obtained was handled in a manner to ensure privacy and protect confidentiality.

\section{Inclusion/exclusion criteria}

We included all children with HD who underwent
Soave procedures between December-January 2007, and December 2018 in our institution. We excluded the children who underwent another surgery technique during past years. Children who underwent laparoscopic or transabdominal operations were also excluded from this study.

\section{Statistical analysis}

Analysis involved descriptive statistics like means, standard deviations, frequency distributions and cross tabulations. For categorical data where comparisons were made between groups, Chi-square statistics or Fisher's exact (in case chi-square was not valid) were used. Multivariate linear regression analysis was used to determine the risk factors associated with the occurrence of mortality and morbidity in the presence of basic characteristics of patients. Data were analyzed using SPSS software version 20. The significance level was less than 0.05 .

\section{Results}

In total, 55 patients were enrolled in our study. Mean age at the time of the second surgery in our study was $108 \pm 10$ days. There were 24 males $(43.6 \%)$ and 31 females $(56.4 \%)$. The general data of the patients are shown in Table I.

Table I. Patient characteristics.

\begin{tabular}{|c|c|c|c|}
\hline \multicolumn{2}{|c|}{ Characteristics } & n/mean \pm S.D. & $\% /$ range \\
\hline \multirow{2}{*}{ Sex } & Male & 24 & 43.6 \\
\hline & Female & 31 & 56.4 \\
\hline \multicolumn{2}{|c|}{$\begin{array}{l}\text { Age at the time of } \\
\text { second surgery }\end{array}$} & $108 \pm 10$ days & (range days - years) \\
\hline \multicolumn{2}{|c|}{ Birth weight } & $2970 \pm 447.27$ & $2100-4100$ \\
\hline \multicolumn{2}{|c|}{ Hospital stay } & $7.36 \pm 4.83$ days & $1-21$ \\
\hline \multirow{2}{*}{$\begin{array}{l}\text { Mode of } \\
\text { delivery }\end{array}$} & C.S & 26 & 47.3 \\
\hline & NVD & 29 & 52.7 \\
\hline \multirow{2}{*}{$\begin{array}{l}\text { States of } \\
\text { pregnancy }\end{array}$} & Term & 41 & 74.5 \\
\hline & Preterm & 14 & 25.5 \\
\hline
\end{tabular}

Comorbidities have been reported in some of the studied patients, as shown in figure 1 .

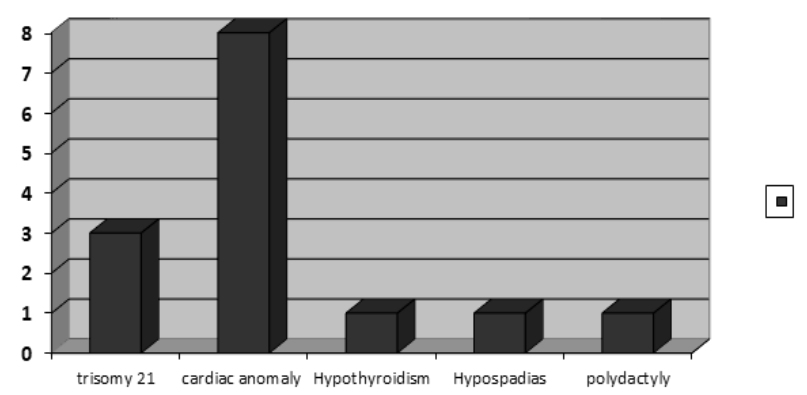

Figure 1. Distribution of comorbidities in the study patients. 
Table II shows the various complications observed following the definitive surgical procedures.

Table II. Early and late post-surgical complications of the patients.

\begin{tabular}{l|c|l|c}
$\begin{array}{l}\text { Early } \\
\text { Complications }\end{array}$ & $\mathrm{N}($ percent) & $\begin{array}{l}\text { Long-term } \\
\text { Complications }\end{array}$ & $\mathrm{N}($ percent) \\
\hline $\begin{array}{l}\text { Death } \\
\text { Leak of } \\
\text { anastomosis }\end{array}$ & $0(0)$ & Death & $0(0)$ \\
Stricture (stenosis) & $1(1.8)$ & Enterocolitis & $8(14.5)$ \\
Infection & $0(0)$ & $\begin{array}{l}\text { Fecal } \\
\text { Incontinency }\end{array}$ & $3(5.5)$ \\
Obstruction & $14(25.5)$ & Obstruction & $15(27.3)$
\end{tabular}

The first operation of all patients was performed in the neonatal period. In this study the complications were evaluated following the second operation. The results showed that $23.6 \%$ of patients had short-term complications and long-term complications occurred in $54.5 \%$ of them. The distribution of disease complications according to the patient's age is shown in Table III. Constipation and obstruction were two major and most common early and late complications which presented in comparison to the other ones. However, the statistical differences observed in these complications in the two age groups were not statistically significant (for constipation $\mathrm{p}=0.4$ and for intestinal obstruction, $\mathrm{p}=0.08$, respectively).

Table III. Complications occurred at different ages in the study patients.

\begin{tabular}{l|c|c|}
\multirow{2}{*}{ Complications } & \multicolumn{2}{|c|}{ Age of patients } \\
\cline { 2 - 3 } & $\begin{array}{c}\text { Less than 5 } \\
\text { months (N) }\end{array}$ & $\begin{array}{c}\text { 5 months to 2 years } \\
(\mathbf{N})\end{array}$ \\
\hline Death & 0 & 0 \\
Leak of anastomosis & 0 & 0 \\
Stricture (stenosis) & 1 & 0 \\
Infection & 0 & 0 \\
Obstruction & 26 & 3 \\
Constipation & 11 & 4 \\
Enterocolitis & 5 & 3 \\
Fecal Incontinency & 1 & 2
\end{tabular}

The short-term and long-term complications of patients in terms of gender is presented in Table IV.

The results showed that there was no statistically significant relationship between the presence of comorbidities and the occurrence of complications in the short-term $(p=0.48)$ and also long-term $(p=0.63)$. There were no cases of post-surgical mortality in our study. No obvious or significant relationship was indicated between early $(\mathrm{p}=0.9)$ as well as late $(\mathrm{p}=0.8)$ complications and mortality in HD patients.
Table IV. Complications following Soave's procedure in terms of gender.

\begin{tabular}{l|c|c|}
\multirow{2}{*}{ Complications } & \multicolumn{2}{|c}{ Sex } \\
\cline { 2 - 3 } Death & Male $(\mathbf{N})$ & Female $(\mathbf{N})$ \\
Leak of anastomosis & 0 & 0 \\
Stricture (stenosis) & 0 & 0 \\
Infection & 0 & 1 \\
Obstruction & 0 & 0 \\
Constipation & 11 & 15 \\
Enterocolitis & 0 & 9 \\
Fecal Incontinency & 0 & 2 \\
\end{tabular}

\section{Discussion}

Hirschsprung's disease (HD) is a rare alimentary tract disease. In the pathogenesis of $\mathrm{HD}$, the migration arrest of enteric neural crest cells (ENCCs) is prominent, leading to the failure of reaching to the hindgut during embryogenesis. A total of $98 \%$ of neonates pass meconium within 24-48 hours after birth, while this fails in patients with HD [21]. There are various techniques for managing the disease. The outcome of each technique is determined by the short-term and long-term complications. The ultimate goal of all these methods is to establish proper bowel movement without fecal incontinence or constipation [22]. In 1964, Soave described the endorectal approach for pull-through. In this procedure, the mucosa-submucosal layer of distal part of the rectum is removed and the normal ganglionic colon is drawn through the muscular cuff of the aganglionic colon and ultimately colo-anal anastomosis is performed [23]. Here, extended dissection is avoided and the internal area of the anal sphincter preserved $[19,24]$. Given the complexity of the etiology, genetics, pathology, and pathophysiology of HD, it is not surprising that adverse consequences appear even after a safe and secure operation. The incidence of complications after treatment of HD is not low. Various factors play a role in such outcomes, including the age of the child at the time of treatment, the duration of the disease, the associated anomalies and the type of surgical procedure [25-27]. It is generally thought that restoring the continuity of digestive tract function at a younger age leads to better control of the defecation by a child in older ages.

In the present study, 55 patients with HD who underwent transanal pullthrough Soave technique during a 12 -year period were evaluated. The results of data analysis showed that most of the patients were female, term and born through NVD. The mean weight of the neonates was $2970 \mathrm{gr}$ (range from 2100 to 4100 grams). The most commonly reported disorder and associated comorbidities in our study were congenital heart diseases, such as ASD, VSD and PDA.

In the study of Hiradfar et al. [28], the dominant population were female. The results of our study in terms of 
neonatal birth weight were similar to those of the Bradnock study [29]. Mohajerzadeh et al conducted a study aimed to compare the complications and consequences of Swenson and Soave surgery techniques in 60 patients with Hirschsprung's disease. They mentioned that the most commonly reported abnormalities were major cardiac disease and trisomy 21 [30]. This association was also seen in other studies [31]. The results obtained in our study are in line with the results of the above studies. The length of hospital stay was 7.36 days for our patients, which was in contrast with the period mentioned by Mohajerzadeh et al [30].

Here in the present study the patients underwent a two-stage operation, and re-operation performed in some cases due to the complications. In the last decade, the development of surgical techniques has significantly improved the quality of life of HD patients. Some studies have suggested that HD patients undergoing one-stage operation had better prognosis than patients undergoing multi-stage surgery $[31,32]$. Sulkowski et al reported that in the majority (77.2\%) of HD patients undergoing pullthrough surgery, a lower rate of readmission and additional surgeries was observed [31]. However, the results of some studies (Sharma and Gupta) contradict these findings, and they stated that $82 \%$ of patients required multi-stage techniques in relation to the dilated bowel [32].

Many complications may occur following the Soave surgery. Although numerous studies have focused on the effectiveness and safety of the Soave technique, clinical data remain inadequate to evaluate the long-term effectiveness of this surgical method.

In our study, $23.6 \%$ of patients had short-term complications and $54.5 \%$ of patients with long-term complications. Obstruction was the most commonly found complication in the short term, as well as constipation and intestinal obstruction were the most findings over the next 2 years of the surgery. Postoperative complications in Soave surgery pediatrics ranged from $14.7 \%$ to $67 \%$ in different studies [33-35]. Chronic constipation and obstruction were prevalent findings in these cases. There was no case of post-operative death in our study.

Enterocolitis is one of the long-term complications of HD surgery. It was noted in $14.5 \%$ of our series, which is similar to the results of other studies [14,36]. In some studies, researchers used different cuff lengths for the Soave technique and found that the incidence of enterocolitis was lower in patients with short cuff (9\% vs. 30\%) [36,37]. Some authors have argued that preoperative enterocolitis significantly increases the incidence of postoperative enterocolitis, due to the predisposing immunologic factors. There was no significant difference between the complications in different age groups. However, the incidence of intestinal obstruction and constipation was higher in patients less than 5 months of age.

This study has certain limitations in design and performance, including selection bias due to the preference of the operating surgeon, and the small sample size that could decrease statistical power. The results should be evaluated over longer time periods with follow-up in multiple centers. The mean operation time is a very important item associated with the occurrence of complications which was not mentioned in the records of our patients. According to the findings of this study, it is suggested that future studies should be conducted as cohort and with the control group, to report more accurate and measurable results. It is also recommended to compare the complications and consequences of the Soave surgical technique with other surgical techniques in order to reduce the complications.

\section{Conclusion}

Surgical techniques have been developed and evolved for the treatment of Hirschsprung's disease over the time. Traditional methods are associated with high rates of short-term and long-term complications. Generally, it is believed that modern surgical techniques such as transanal pull-through Soave surgery have been helpful in reducing the incidence of such complications and was both feasible and safe for the management of patients with HD. Bowel obstruction and constipation were two prevalent early and long-term complications which have been resolved by reoperation and adequate and suitable nutritional regimens.

\section{References}

1. Langer JC. In: Principle and Practice of Pediatric Surgery. Chapter 4. Colombani PM, Foglio RP, Skinner MA, Oldham KT (eds.). Philadelphia: Lippincott, Williams and Wilkins; 2005. vol 1: pp. 2,1348-1363.

2. Teitelbaum DH, Coran AG. In: Hirschsprung's disease and related neuromuscular. pediatric surgery (six edition): vol 2: chapter 99: pp. 1514-1559.

3. Swenson O. Hirschsprung's disease: a review. Pediatrics. 2002;109:914-918.

4. Swenson O, Bill AH Jr. Resection of rectum and rectosigmoid with preservation of the sphincter for benign spastic lesions producing megacolon; an experimental study. Surgery. 1948;24:212-220.

5. Swenson O, Sherman JO, Fisher JH. Diagnosis of congenital megacolon: an analysis of 501 patients. J Pediatr Surg. 1973;8:587-594.

6. Höllwarth ME, Rivosecchi M, Schleef J, Deluggi S, Fasching G, Ceriati E, et al. The role of transanal endorectal pull-through in the treatment of Hirschsprung's disease - a multicenter experience. Pediatr Surg Int. 2002;18:344-348.

7. Langer JC, Seifert M, Minkes RK. One-stage Soave pullthrough for Hirschsprung's disease: a comparison of the transanal and open approaches. J Pediatr Surg. 2000;35:820822.

8. Brisinda G, Vanella S, Cadeddu F, Marniga G, Mazzeo P, Brandara F, et al. Surgical treatment of anal stenosis. World J Gastroenterol. 2009;15:1921-1928. 
9. Campobasso P, Salano F, Cimaglia ML, Cappellari F, Scalabrin U, Belloli G. Hirschsprung disease: Results of surgical treatment. Pediatr Med Chir. 1986;8:659-664.

10. Joseph VT, Sim CK. Experience in the surgical management of Hirschsprung's disease. Ann Acad Med Singapore. 1987;16:518-526.

11. Campobasso P, Belloli G. Chronic constipation in children. Pediatr Med Chir. 1988;10:241-250.

12. Joseph VT, Sim CK. Problems and pitfalls in the management of Hirschsprung's disease. J Pediatr Surg 1988;23:398-402.

13. Neilson IR, Yazbeck S. Ultrashort segment Hirschsprung's disease: myth or reality. J Pediatr Surg. 1990;25:1135-1138.

14. Watanatittan S, Suwatanaviroj A, Limprutithum T, Rattanasuwan T. Association of Hirschsprung's disease and anorectal malformation. J Pediatr Surg. 1991;26:192-195.

15. De La Torre L, Langer JC. Transanal endorectal pull-through for Hirschsprung disease: technique, controversies, pearls, pitfalls, and an organized approach to the management of postoperative obstructive symptoms. Semin Pediatr Surg. 2010;19:96-106

16. Levitt MA, Dickie B, Peña A. Evaluation and treatment of the patient with Hirschsprung disease who is not doing well after a pull-through procedure. Semin Pediatr Surg. 2010;19:146-153.

17. Mundt E, Bates MD. Genetics of Hirschsprung disease and anorectal malformations. Semin Pediatr Surg. 2010;19:107117.

18. Guinard-Samuel V, Bonnard A, De Lagausie P, PhilippeChomette P, Alberti C, El Ghoneimi A, et al. Calretinin immunohistochemistry: a simple and efficient tool to diagnose Hirschsprung disease. Mod Pathol. 2009;22:1379-1384.

19. Georgeson KE, Cohen RD, Hebra A, Jona JZ, Powell DM, Rothenberg SS, et al. Primary laparoscopic-assisted endorectal colon pull-through for Hirschsprung's disease: a new gold standard. Ann Surg. 1999;229:678-682; discussion 682-683.

20. Keckler SJ, Yang JC, Fraser JD, Aguayo P, Ostlie DJ, Holcomb GW 3rd, et al. Contemporary practice patterns in the surgical management of Hirschsprung's disease. J Pediatr Surg. 2009;44:1257-1260.

21. Mabula JB, Kayange NM, Manyama M, Chandika AB, Rambau PF, Chalya PL. Hirschsprung's disease in children: a five year experience at a university teaching hospital in northwestern Tanzania. BMC Res Notes. 2014;7:410.

22. Baxter KJ, Bhatia AM. Hirschsprung's disease in the preterm infant: implications for diagnosis and outcome. Am Surg. 2013;79:734-738.

23. Soave F. Hirschsprung's disease: a new surgical technique. Arch Dis Child. 1964;39:116-124.

24. Ieiri S, Nakatsuji T, Akiyoshi J, Higashi M, Hashizume M, Suita $\mathrm{S}$, et al. Long-term outcomes and the quality of life of Hirschsprung disease in adolescents who have reached
18 years or older--a 47-year single-institute experience. J Pediatr Surg. 2010;45:2398-2402.

25. Stensrud KJ, Emblem R, Bjørnland K. Functional outcome after operation for Hirschsprung disease--transanal vs transabdominal approach. J Pediatr Surg. 2010;45:16401644.

26. Anderson JE, Vanover MA, Saadai P, Stark RA, Stephenson JT, Hirose S. Epidemiology of Hirschsprung disease in California from 1995 to 2013. Pediatr Surg Int. 2018;34:12991303.

27. Gunadi, Karina SM, Dwihantoro A. Outcomes in patients with Hirschsprung disease following definitive surgery. BMC Res Notes. 2018;11:644.

28. Hiradfar M, Sharifi N, Khajedaluee M, Zabolinejad N, Taraz Jamshidi S. Calretinin Immunohistochemistery: An Aid in the Diagnosis of Hirschsprung's Disease. Iran J Basic Med Sci. 2012;15:1053-1059.

29. Bradnock TJ, Walker GM. Evolution in the management of Hirschsprung's disease in the UK and Ireland: a national survey of practice revisited. Ann R Coll Surg Engl. 2011;93:34-38.

30. Mohajerzadeh L, Khaleghnejad Tabari A, Rouzrokh M, Mirshemirani AR, Sadeghian N, Ghoroubi J, et al. Comparison between Swenson and Soave Pull-Through in Hirschprung Disease. Ann Colorectal Res. 2015;3:e32700.

31. Sulkowski JP, Cooper JN, Congeni A, Pearson EG, Nwomeh BC, Doolin EJ, et al. Single-stage versus multi-stage pullthrough for Hirschsprung's disease: practice trends and outcomes in infants. J Pediatr Surg. 2014;49:1619-1625.

32. Sharma S, Gupta DK. Hirschsprung's disease presenting beyond infancy: surgical options and postoperative outcome. Pediatr Surg Int. 2012;28:5-8.

33. Widyasari A, Pravitasari WA, Dwihantoro A, Gunadi. Correction to: Functional outcomes in Hirschsprung disease patients after transabdominal Soave and Duhamel procedures. BMC Gastroenterol. 2018;18:110.

34. Widyasari A, Pravitasari WA, Dwihantoro A, Gunadi. Functional outcomes in Hirschsprung disease patients after transabdominal Soave and Duhamel procedures. BMC Gastroenterol. 2018;18:56.

35. Jiao C, Yu D, Li D, Wang G, Feng J. A Long-Term FollowUp of a New Surgery Method: Laparoscope-Assisted Heart-Shaped Anastomosis for Hirschsprung's Disease. J Laparoendosc Adv Surg Tech A. 2018;28:471-475.

36. Ram AD, Scholfield DW, Pimpalwar A. Novel technique of Mapping Biopsies during laparoscopic assisted transanal Soave endorectal pull-through surgery for Hirschsprung's disease's. Ann R Coll Surg Engl. 2017;99:504.

37. Khazdouz M, Sezavar M, Imani B, Akhavan H, Babapour A, Khademi G. Clinical outcome and bowel function after surgical treatment in Hirschsprung's disease. Afr J Paediatr Surg. 2015;12:143-147. 